\title{
Oral Malocclusion and Its Relation to Nutritive and Non-nutritive Habits in School Children
}

\author{
Antonia Alcaina Lorente ${ }^{1, *}$, Olga Cortes ${ }^{1}$, Sonia Guzmán ${ }^{1}$, Ascensión Vicente ${ }^{2}$, Nuria Garrido ${ }^{3}$ \\ ${ }^{1}$ Department of Pediatric Dentistry, School of Dental Medicine, University of Murcia, Spain \\ ${ }^{2}$ Department of Orthodontics, School of Dental Medicine, University of Murcia, Spain \\ ${ }^{3}$ School Psychology, University of Murcia, Spain
}

Copyright $\bigcirc 2019$ by authors, all rights reserved. Authors agree that this article remains permanently open access under the terms of the Creative Commons Attribution License 4.0 International License

\begin{abstract}
Oral habits are customs acquired by the repetition of a series of events that serve to calm an emotional need. Early diagnosis of these anomalous habits is crucial to the early prevention or correction of malocclusions. The objective of the study is to determine the prevalence of malocclusion in school and its possible relationship with the nutritive and non-nutritive habits. Design: Cross- sectional study on 113 school children with ages between 3 and 8 years old. Surveys were carried out from parents related to nutritional habits and non-nutritive. Results: The prevalence of children with malocclusion class II is $34.5 \%$, followed by overjet $(33.6 \%)$, cross bite $(10.6 \%)$, open bite $(9.7 \%)$ and the habits of lip interposition $(15 \%)$, lingual habit $(11.5 \%)$ and oral breath $(7.1 \%)$. There is a statistically significant relationship $(p<0,05)$ between the habit of snoring at night with the overjet $(p=0,001)$, also with class II molar $(\mathrm{p}=0.037)$ and with oral breath $(\mathrm{p}$ $=0.016)$. Finally, there is a statistically significant relationship between prolonged bottle habit $(p=0.047)$ with the posterior crossbite. Conclusions: The habits of nutritive and non-nutritive sucking in the early stages of the childhood, may be a risk factor for the development of class II molar, increased overjet and posterior crossbite malocclusion.
\end{abstract}

Keywords Habits, Malocclusion, Children

\section{Introduction}

Malocclusion is accompanied by a morphological and functional disorder of the bone, muscle, and dental components of the stomatognathic system. Genetic and environmental factors play an important role in the development of malocclusion [1].

Malocclusion is common in children and its prevalence varies from $20 \%$ to $93 \%$ across different age groups [2]. In 2015, the Organización colegial de Dentistas de España
(Spanish Dental association) published an Oral Health Survey [3], which verified that at the age of 12 years, $10.9 \%$ of children wear orthodontic apparatus, and $21.1 \%$ present moderate to severe malocclusion. At the age of 15 years, $17.8 \%$ wear orthodontic apparatus, while $16.6 \%$ present moderate to severe malocclusion.

Among pre-school children the most common occlusal disorders are anterior open bite, overjet, Class II malocclusion and posterior crossbite [4].

Some anomalous oral habits are physiological, and among these the most notable are nasal respiration, mastication, swallowing. Non-physiological habits include non-nutritive sucking (thumb sucking, pacifier sucking, nail biting, tooth grinding, snoring) and nutritive sucking (breast feeding, bottle feeding). Anomalous habits can alter the normal development of the stomatognathic system, producing an imbalance between internal and external muscular forces. Such habits modify the positions of the teeth, the relationship between the dental arches, and their shape $[5,6]$.

The prevalence of anomalous oral habits varies between $1.1 \%$ and $67.9 \%$ [7]. It has been observed that if these habits persist beyond the age of 3 years, they can alter the normal development of the dental arches at the end of the primary dentition period, occasioning anterior open bite [8], as well as posterior crossbite. According to most researchers, thumb sucking is one of the most harmful habits to the development of normal occlusion $[9,10]$. Pacifier sucking is the most common non-nutritive sucking habit [11].

Some studies have suggested that the protective effects of breastfeeding during the first months of life act against the development of occlusal disorders, favoring the sagittal growth of the mandible and a correct intermaxillary relationship [12]. As well as being a protective factor against other diseases in infancy, breastfeeding prevents the development of posterior crossbite in primary teeth and mixed teeth, and also prevents the infant from developing sucking habits [13]. The World Health Organization 
(WHO) recommends that breastfeeding should continue until at least the age of 6 months [12]. Absence or short duration of breastfeeding results in increased use of feeding bottles, which can lead to reduced strength in the muscles involved in feeding, which may compromise correct mandibular development [14].

Early diagnosis of these anomalous habits is crucial to the early prevention or correction of malocclusions.

The objective of this study was to determine the prevalence of malocclusions in a population of school children aged 3-8 years and their relation to nutritive and non-nutritive oral habits.

\section{Materials and Methods}

This cross-sectional study was conducted among 113 school children aged between 3 and 8 years, attending a primary school in the city of Albacete (Spain). This study was approved by the Research Ethics Committee of the University of Murcia. The study took place during the 2014-15 school years. Having provided the school with information about the project - which consisted of a survey and clinical examination - the headmaster gave permission to proceed with the consensus of the directors and teaching staff.

\subsection{Survey Design}

Table 1 shows the questions included in the survey. Permission for the children to take part was sought from their parents, informing them about the study and its purpose, and giving them the survey which consisted of 14 questions/items. The first section of the survey registered identification details, and the second oral habits, both nutritive (breastfeeding and bottle feeding) and non-nutritive (thumb-sucking, dummies, nail-biting, bruxism and snoring). Inclusion criteria were as follows:

Children aged 3-8 years, whose parents gave written informed consent for them to take part in the study.

\subsection{Clinical Examination}

The clinical examination was carried out by two experienced dentists. The visual inspection of the children's oral cavity was performed at the school. Exploration was conducted following criteria recommended by the WHO including good natural light. ${ }^{15}$ Prior to the start of the study the examiner was calibrated in the department of Pediatric Dentistry the intra-examiner reliability coefficient was 0.86 . Examination registered the following variables: molar Angle Class and the presence of increased overjet, posterior crossbite, anterior open bite, tongue thrusting habit, oral respiration, and lip interposition.

The sagital interarch relationship was classified according to the deciduous canine relationship as Angle class I, class II, or class III, with class I considered normal occlusion, class I canine and molars bilareral or class I canine and molars unilateral, and class II or class III considered altered.

Posterior crossbite was diagnosed when a reverse occlusal relationship was observed in the transverse plane between at least one posterior tooth. (deciduous canine or molar).

Anterior open bite was defined as the abscense of vertical overlap between the upper and lower teeth in the anterior region.

Overjet was measured from the palatal surface of the mesial corner of the most protruded fully erupted maxillary incisor to the labial surface of the corresponding mandibular incisor. The degree of overjet was recorded in millimeters. In this study, an overjet of greater than $4 \mathrm{~mm}$ was considered an increased overjet.

Table 1. Oral Habits Questionnaire

\begin{tabular}{|c|l|c|}
\hline 1 & Sex: & M/F \\
\hline 2 & Age: & \\
\hline 3 & School year: & \\
\hline 4 & Place of birth: & \\
\hline 5 & Number of siblings: & \\
\hline 6 & Birth order: & \\
\hline 7 & Breastfeeding: Up to what age? & \\
\hline 8 & $\begin{array}{l}\text { Nocturnal bottle feeding or bottle feeding while } \\
\text { infant slept: Up to what age? }\end{array}$ & \\
\hline 9 & Bottle feeding? Up to what age? & \\
\hline 10 & Does/did he/she suck his/her thumb? Up to what age? & \\
\hline 11 & Does/did he/she bite his/her nails? Up to what age? & \\
\hline 12 & Does he/she grind his/her teeth during the night? & \\
\hline 13 & Does he/she wake up at night? & \\
\hline 14 & Does he/she snore? & \\
\hline
\end{tabular}

\subsection{Statistical Analysis}

Statistical analysis was performed using SPPS 19.0 software at the department of Biostatistics, Faculty of Medicine, University of Murcia (Spain). Descriptive statistics were calculated for all variables analyzed in the study. Associations between qualitative variables were estimated using the chi-squared test to identify significant relations. The level of statistical significance was set at $\mathrm{p}<0.05$.

\section{Results}

\subsection{Descriptive Analysis}

The sample consisted of 113 children aged 3-8 years, 58 boys $(51 \%)$ and 55 girls (49\%). Sample distribution by age is shown in Table 2. 
Table 2. Sample distribution by age

\begin{tabular}{|c|c|c|}
\hline Age & Frequency $(\mathrm{N})$ & Percentage $(\%)$ \\
\hline 3 years & 14 & $12.4 \%$ \\
4 years & 20 & $17.7 \%$ \\
5 years & 24 & $21.2 \%$ \\
6 years & 25 & $22.1 \%$ \\
7 years & 21 & $18.6 \%$ \\
8 years & 9 & $8 \%$ \\
\hline
\end{tabular}

The study found a prevalence of children with molar Class II malocclusion of $34.5 \%$, this being the most frequent malocclusion, followed by overjet $(33.6 \%)$, posterior crossbite $(10.6 \%)$, anterior open bite $(9.7 \%)$, and molar Class III (7.1\%). As for anomalous habits, the study found lip interposition (15\%), tongue thrusting habit (11.5\%), and oral respiration (7.1\%). (Figure 1) The most common non-nutritive habit among the children was pacifier sucking with a frequency of $43.5 \%$ up to the age of 2 years, followed by nail biting (29.6\%), bruxism (27.9\%), snoring $(23.1 \%)$, pacifier sucking over the age of 2 years $(22.2 \%)$ and thumb sucking $(9.3 \%)$. (Table 3 and Figure 2 )

The most frequent nutritive habit was breastfeeding beyond the age of 2 years with a frequency of $48.1 \%$, followed by breastfeeding up to the age of 6 months (31.5\%), bottle feeding up to 6 months $(29.1 \%)$ and bottle feeding beyond the age of 2 years $(0.9 \%)$. (Table 3 and Figure 3)

\subsection{Analysis of Variables}

Analysis was performed using contingency tables to determine the relations between variables. Table 4 details the variables that showed relations with malocclusions. A statistically significant relation $(p<0.05)$ was identified between nighttime snoring and increased overjet $(p=$ 0.001 ); another significant relation between snoring and molar Class II $(\mathrm{p}=0.037)$ and between snoring and oral respiration $(\mathrm{p}=0.016)$. Lastly, a significant relation was found between prolonged bottle feeding and posterior crossbite $(\mathrm{p}=0.008)$

Table 3. Frequency of nutritive and non-nutritive habits

\begin{tabular}{|c|c|c|}
\hline $\mathrm{N}=130$ & Frequency & Percentage \\
\hline \multicolumn{3}{|l|}{ Non-nutritive habits } \\
\hline Pacifier sucking & 37 & $34.3 \%$ \\
\hline No & 47 & $43.5 \%$ \\
\hline Up to 2 years & 24 & $22.2 \%$ \\
\hline \multicolumn{3}{|l|}{ Thumb-sucking } \\
\hline No & 98 & $90.7 \%$ \\
\hline Yes & 10 & $9.3 \%$ \\
\hline \multicolumn{3}{|l|}{ Nail-biting } \\
\hline No & 76 & $70.4 \%$ \\
\hline Yes & 32 & $29.6 \%$ \\
\hline \multicolumn{3}{|l|}{ Bruxism } \\
\hline No & 75 & $72.1 \%$ \\
\hline Yes & 29 & $27.9 \%$ \\
\hline \multicolumn{3}{|l|}{ Snoring } \\
\hline No & 83 & $76.9 \%$ \\
\hline Yes & 25 & $23.1 \%$ \\
\hline \multicolumn{3}{|l|}{ Nutritive habits } \\
\hline \multicolumn{3}{|l|}{ Breastfeeding } \\
\hline No & 22 & $20.4 \%$ \\
\hline Up to 2 years & 34 & $31.5 \%$ \\
\hline Over 2 years & 52 & $48.1 \%$ \\
\hline \multicolumn{3}{|l|}{ Bottle feeding } \\
\hline No & 77 & $70 \%$ \\
\hline Up to 2 years & 32 & $29.1 \%$ \\
\hline Over 2 years & 1 & $0.9 \%$ \\
\hline
\end{tabular}

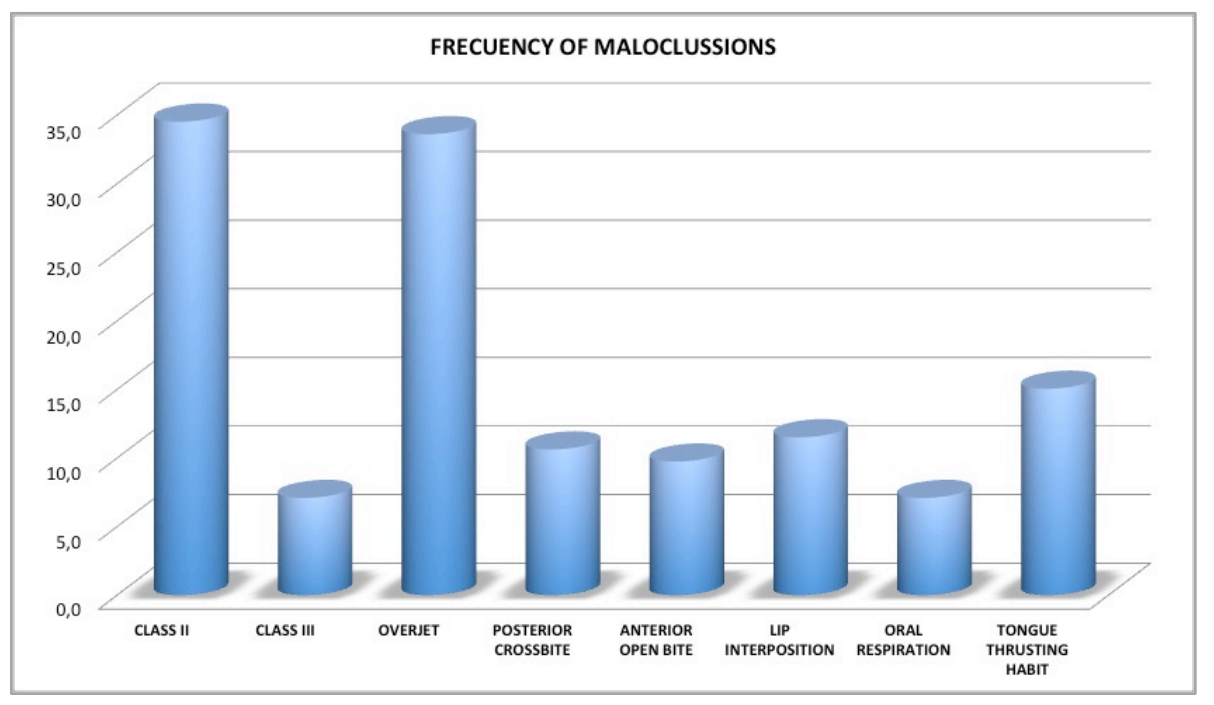

Figure 1. Frequency of malocclusions 


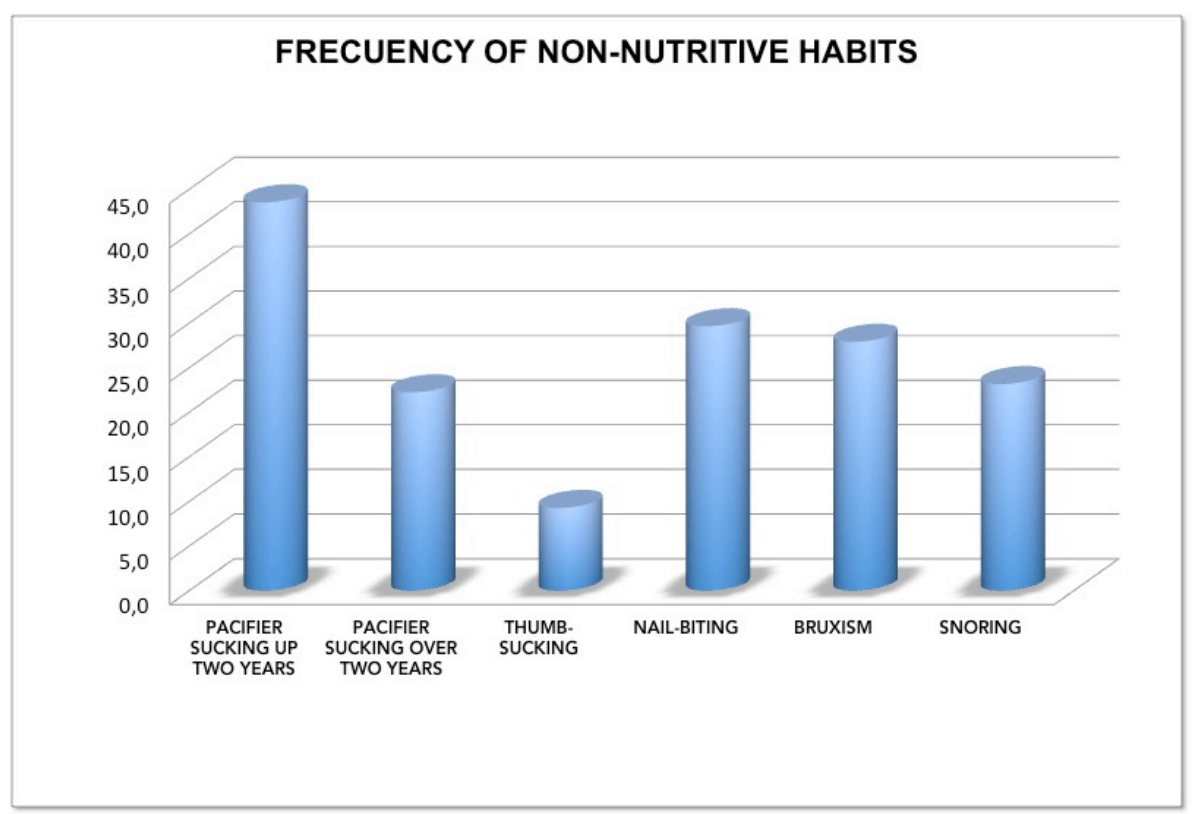

Figure 2. Frequency of non-nutritive habits

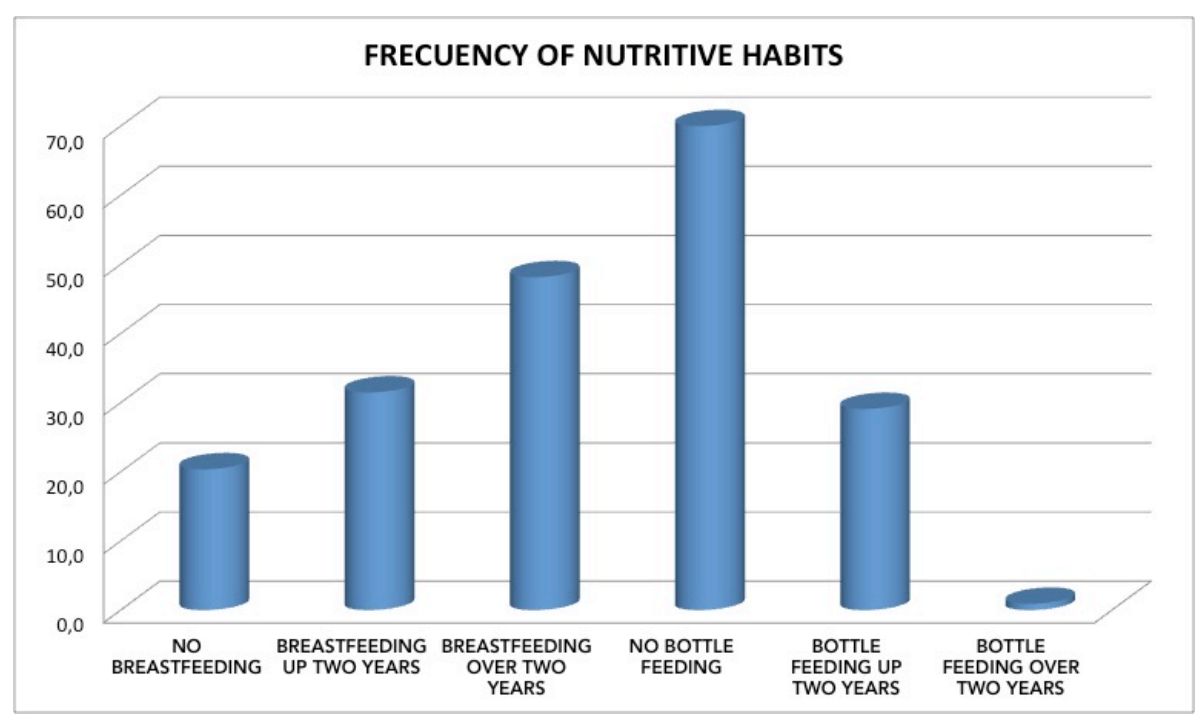

Figure 3. Frequency of Nutritive Habits 
Table 4. Relation between nutritive and non-nutritive habits with maloclussions

\begin{tabular}{|c|c|c|c|c|c|c|c|c|c|c|c|c|c|c|}
\hline \multirow[t]{2}{*}{ habit } & \multicolumn{2}{|c|}{ Molar class } & \multicolumn{2}{|c|}{ Increased overjet } & \multicolumn{2}{|c|}{ Posterior crossbite } & \multicolumn{2}{|c|}{ Anterior open bite } & \multicolumn{2}{|c|}{ Lip interposition } & \multicolumn{2}{|c|}{ Oral respiration } & \multicolumn{2}{|c|}{ Tongue thrusting habit } \\
\hline & $\begin{array}{c}\text { Chi-squuare } \\
\text { test }\end{array}$ & $\mathrm{P}$ & $\begin{array}{c}\text { Chi-squuare } \\
\text { test }\end{array}$ & $\mathrm{P}$ & $\begin{array}{c}\text { PChi-squuare } \\
\text { test }\end{array}$ & $\mathrm{P}$ & $\begin{array}{c}\text { Chi-squuare } \\
\text { test }\end{array}$ & $\mathrm{P}$ & $\begin{array}{c}\text { Chi-squuare } \\
\text { test }\end{array}$ & $\mathrm{P}$ & $\begin{array}{c}\text { Chi-squuare } \\
\text { test }\end{array}$ & $\mathrm{P}$ & Chi-squuare test & $\mathrm{P}$ \\
\hline $\begin{array}{l}\text { Pacifier } \\
\text { sucking }\end{array}$ & 3.372 & 0.498 & 0.246 & 0.884 & 3.364 & 0.186 & 5.286 & 0.071 & 0.061 & 0.97 & 2.185 & 0.335 & 0.497 & 0.78 \\
\hline Thumb sucking & 1.307 & 0.52 & 0.055 & 0.559 & 0.007 & 0.638 & 1.16 & 0.269 & 3.358 & 0.1 & 1.08 & 0.553 & 0.274 & 0.51 \\
\hline Nail-biting & 1.173 & 0.556 & 2.22 & 0.136 & 2.037 & 0.154 & 0.033 & 0.857 & 0.009 & 0.924 & 3.638 & 0.056 & 0 & 0.983 \\
\hline Bruxism & 3.718 & 0.156 & 1.379 & 0.24 & 0.145 & 0.703 & 2.161 & 0.142 & 3.012 & 0.083 & 2.108 & 0.147 & 0.555 & 0.456 \\
\hline Snoring & 4.107 & $0.037^{*}$ & 17.592 & $0.001 *$ & 0.061 & 0.804 & 1.202 & 0.273 & 1.948 & 0.163 & 7.521 & $0.016^{*}$ & 0.002 & 0.968 \\
\hline Breastfeeding & 3.451 & 0.485 & 0.091 & 0.955 & 0.275 & 0.872 & 2.244 & 0.326 & 1.062 & 0.588 & 3.865 & 0.145 & 0.273 & 0.872 \\
\hline Bottle & 4.522 & 0.34 & 0.768 & 0.681 & 9.669 & $0.008^{*}$ & 0.404 & 0.817 & 0.15 & 0.928 & 4.69 & 0.096 & 3.25 & 0.197 \\
\hline
\end{tabular}

The chi-square test was used to analyze the associations between non-nutritive and nutritive sucking and occlusal characteristics

${ }^{*}$ Comparisons are significantly different, $\mathrm{P}<0.05$ 


\section{Discussion}

The present study focused on those malocclusions that are likely to occur among the study's target population, school children aged 3-8 years, and their possible relationships with nutritive and non-nutritive habits. This is an age span when important changes take place, including the shedding of primary teeth and the appearance of permanent dentition, and rapid intellectual and neuromuscular development. With regard to method, the study was planned to meet clearly defined objectives, diagnosing malocclusions according to recommendations made by the WHO for children in this age group [15].

As for the prevalence of malocclusion, it was found that $34.5 \%$ of the children presented molar Class II, followed by increased overjet $(33.6 \%)$, crossbite $(10.6 \%)$, anterior open bite $(9.7 \%)$, and molar Class III $(7.1 \%)$. As for oral anomalous habits the study found $15 \%$ with lip interposition, $11.5 \%$ with a tongue thrusting habit, and $7.1 \%$ with oral respiration. In the Oral Health Survey [3], it was found that at the age of 12 years, $21.1 \%$ present moderate/severe malocclusion, a lower percentage than that obtained in the present study. It is important to take into account the difficulty - affirmed by the WHO - of diagnosing these disorders, as the classification of malocclusions as slight, moderate or severe does not permit a precise characterization of the pathology [15].

For some authors [16], anterior open bite shows a prevalence of $17.7 \%$ in mixed dentition and of these cases $36.3 \%$ are caused by genetic patterns and prolonged sucking habits. In the present study, the percentage of children with open bite was rather less (9.7\%).

Oral anomalous habits can initiate, predispose, or aggravate dental malocclusions although they may not be the main etiological factor governing their appearance. Nevertheless, numerous studies have related the various oral anomalous habits with the presence of occlusal pathology.

The most common non-nutritive habit found in the present study was pacifier sucking with a frequency of $43.5 \%$ up to the age of 2 years, followed by nail-biting $(29.6 \%)$, bruxism $(27.9 \%)$, snoring $(23.1 \%)$, pacifier sucking beyond the age of 2 years $(22.2 \%)$ and thumb sucking $(9.3 \%)$.

The present findings for thumb-sucking among children in Albacete (Spain) are very similar to those obtained by Domínguez et al. [17] (11.7\%) in children in Andalucía (Spain), and Farsi and Salana [18] (10.4\%) in Saudi children. The differences in prevalence show how these habits vary according to population and age group. Furthermore, some authors consider thumb sucking normal until the age of 4 years or even 5 , a situation that would alter the frequency of what is considered anomalous behavior.

Warren and Bishara [19], in a study of children with primary teeth found a relationship between pacifier sucking beyond the age of 2 years and posterior crossbite, and between thumb sucking and overjet, and a tendency for both habits to relate to anterior open bite. These results coincide with another study of 503 school children aged 5-7 years, which found a significant relation between thumb sucking and anterior open bite and posterior crossbite. But the present study did not identify a significant relation between pacifier/thumb sucking and crossbite and overjet; this might be due to the smaller sample size investigated.

An important factor with a bearing on the results of any study on this topic is the duration of the oral habit. In this sense, it is understood that if sucking habits persist beyond the age of 3 years, this will predispose the child to developing anterior open bite [8].

The results of this study showed a significant association between nighttime snoring and overjet. Patients who snore are associated with overjet. A statistically significant relation was also found between nighttime snoring and Class II malocclusion, and with oral respiration.

The prevalence of bruxism varies between $4 \%$ and $96 \%$ [20-22], due to the different types of bruxism (unspecified, sleep bruxism, and sleep bruxism), the diagnostic method applied, and the characteristics of the population studied. In the present study, $27.9 \%$ of the sample presented bruxism although no significant relation was found between bruxism and malocclusion. Bruxism is of multifactorial etiology [23]. There is no clear evidence to suggest that bruxism can produce malocclusion [24]. But perhaps there is need for further research into possible connections between bruxism and malocclusion.

The most common nutritive habit identified in the present study was breastfeeding beyond the age of 2 years with a frequency of $48.1 \%$, followed by breastfeeding up to the age of 2 years $(29.1 \%)$ and bottle feeding beyond 2 years $(0.9 \%)$.

In the absence of breastfeeding, or when breastfeeding continues for less than 6 months, this results in bottle feeding, which leads to less strength in the muscles involved in feeding; this can alter mandibular development [14]. One study of children [25] observed a direct relation between breastfeeding continuing for under 6 months and the development of posterior crossbite, accompanied by a lack of space in the upper maxilla.

The results of the present study found a statistically significant relation between the bottle feeding habit continuing beyond the age of two years and crossbite. There are various mechanisms involved in the connection between bottle feeding and malocclusion: 1) less muscular strength is required to extract milk from a bottle, which leads to inadequate mandibular growth; 2) the tongue only acts to control the milk supply and so these children show greater prevalence of developing atypical swallowing patterns and tongue thrusting habits; 3) $60 \%$ of bottle-fed children present oral respiration which can compromise occlusion [26]. Nevertheless, Narbutyte et al. [27] consider 
that there is insufficient evidence to relate bottle feeding with the development of skeletal disorders.

In the first stages of life it is important to detect these anomalous habits in order to avoid future occlusal disorders, bearing in mind that these are factors that predispose the child to malocclusion but are not the only reason why a malocclusion may develop. Further studies, with larger samples are needed to obtain conclusive clinical data.

\section{Conclusions}

Nutritive and non-nutritive oral habits during the early stages of childhood may be a risk factor for developing malocclusions such as molar Class II, increased overjet, and posterior crossbite. Early diagnosis of the anomalous habits may help prevent malocclusion.

\section{Acknowledgements}

The authors thank the primary school where the study was conducted, its directors and teaching staff for their cooperation and support and, of course, the children who took part, and their parents.

\section{REFERENCES}

[1] Yamaguchi H, Sueishi H. Malocclusion associated with abnormal posture. Bull Tokyo Dent Coll 2003; 44 (2): 43-54.

[2] Gois E, Vale M, Paiva S, Abreu MH, Serra-Negra JM, Pordeus IA. Incidence of maloclussion between primary and mixed dentitions among Brazilian children. A 5-year longitudinal study. Angle Orthod, 2012; 82(3): 495-500.

[3] Libro Blanco. Encuesta poblacional. La Salud Bucodental en España 2015. Madrid: Grupo ICM de Comunicación.

[4] Warren J, Staylon L, Bishara SE, Ley SM, Yonezu T, Karellis MJ. Effects of non-nutritive sucking habits on occlusal characteristics in the mixed dentition. Pediatr Dent, 2005; 27 : 445-50.

[5] Klocke A, Nanda R, Kahl-Nieke B. Anterior open bite in the deciduous dentition: Longitudinal follow-up and craneofacial growth considerations. Am J Orthod Dentofacial Orthop, 2002; 122: 353-58.

[6] Mistry P, Moles D, O'Neill J, Noar J. The occlusal effects of digit sucking habits amongst school children in Northamptonshire (UK). J Orthod, 2010; 37: 87-92

[7] Quashie-Williams R, DaCosta O, Isiekwe M. Oral habits, prevalence and effects on oclussion of 4-15 year old school children in Lagos, Nigeria. Nigerian Postgrad Med J, 2010; 17: 113-17.

[8] Dimberg L, Lennartsson B, Soderfeldt B, Bondemark L.
Malocclusions in children at 3 and 7 years of age: a longitudinal study. Eur J Orthod, 2013; 35: 131-37.

[9] Larsson E. Sucking, Chewing and Feeding Habits and the development of crossbite: a longitudinal study of girls from birth to 3 years of age. Angle Orthod 2000; 71 (2): 116-9.

[10] Bishara SE, Larsson E. Dent Assist Finger habits: their effects and their treatments-part 1. Dent Assist 2007; 76 (1):14-6.

[11] Bishara SE, Larsson E. Finger habits: their effects and their treatments-part 2. Dent Assist 2007; 76 (2):16-8.

[12] Romero CC, Scavone-Junior H, Garib DG, Cotrim-Ferreira FA, Ferreira RI. Breastfeeding and non-nutritive sucking patterns related to the prevalence of anterior open bite in primary dentition. J Appl Oral Sci 2011; 19 (2): 161-8.

[13] Cristiane LF, Luz Daniela GC, Rafael Aranza. Association between breatfeeding duration and mandibular retrusion: A cross-sectional study of children in the mixed dentition. Am J Orthod Dentofacial Orthop 2006; 130: 531-4.

[14] Viggiano D, Fasano D, Monaco G, Strohmenger L. Breastfeeding, bottle feeding and non-nutritive sucking; effects on occlusion in deciduous dentition. Arch Dis Child 2004; 89 (12): 1121-3.

[15] Organización Mundial de la Salud. Encuestas de Salud Bucodental. Métodos Básicos. 4ºd. Ginebra: OMS; 1997.

[16] Cozza P, Baccetti T, Franchi L, Mucedero M, Polimeni A. Sucking habits and facial hyperdivergency as risk factors for anterior open bite in the mixed dentition. Am J Orthod Dentofacial Orthop 2005; 128(4): 517-9.

[17] Domiínguez Reyes A, Galán González A, Aznar Martín T, Marín Castro I, Succión digital y parámetros oclusales: Estudios en niños de 3 a 6 años de edad. Ortod Esp 1999; 39: 143-7.

[18] Farsi NM, Salama FS. Sucking habits in Saudi children: Prevalence, contributing factors and effects on the primary dentition. Pediatr Dent 1997; 19: 28-33.

[19] Warren JJ, Bishara SE. Duration of nutritive and nonnutritive sucking behaviors and their effects on the dental arches in the primary dentition. Am J Orthod Dentofacial Orthop 2002; 121(4): 347-56.

[20] Kasparaviciene K, Sidlauskas A, Zasciurinskiene E, Vasiliauskas A, Juodzbalys G, Sidlauskas M, Marmaite U. The prevalence of malocclusion and oral habits among 5-7-year-old children. Med Sci Monit. 2014; 20: 2036-42.

[21] Attanasio R. Nocturnal bruxism and its clinical management. Dent Clin North Am 1991; 35(1):245-52.

[22] Lavigne GJ, Montplaisir JY. Restless legs syndrome and sleep bruxism: prevalence and association among Canadians. Sleep. 1994; 17(8):739-43.

[23] Lobbezoo F, Ahlberg J, Manfredini D, Winocur E. Are bruxism and the bite causally related? J Oral Rehabil 2012; 39(7): 489-501.

[24] Johansson A, Omar R, Carlsson GE. Bruxism and prosthetic treatment: a critical review. J Prosthodont Res. 2011; 55(3):127-36

[25] Chen X, Xia B, Ge L. Effects of breast-feeding duration, 
bottle-feeding duration and non-nutritive sucking habits on the occlusal characteristics of primary dentition. BMC Pediatr. 2015; 15:46.

[26] Carrascoza KC, Possobon RF, Tomita LM, Moraes AB. Consequences of bottle-feeding to the oral facial development of initially breastfed children. J Pediatr (Rio J). 2006; 82(5):395-7. Epub 2006 Sep 21.

[27] Narbutytė I, Narbutytė A, Linkevičienè L. Relationship between breastfeeding, bottle-feeding and development of malocclusion. Stomatologija. 2013; 15(3):67-72. 